\title{
INTERGRATED DROUGHT RISK INDICES FROM CLIMATE BASED AND SATTLELITE BASED OBSERVATION FOR AGRICULTURAL DROUGHT MONITORING IN THAILAND
}

\author{
Kalyanee SUWANPRASERT ${ }^{1}$, Shinta SETO ${ }^{2}$ and Sudsaisin KAEWRUENG 3 \\ ${ }^{1}$ Doctoral student, Faculty of Agriculture, Kasetsart University (50 Phaholyothin Rd., Bangkok, 10900, Thailand) \\ ${ }^{2}$ Member of JSCE, Dr. of Eng., Project Assoc. Prof., Institute of Industrial Science, The University of Tokyo (4-6-1 \\ Komaba, Meguro, Tokyo 153-8505, Japan) \\ ${ }^{3}$ Dr. of Eng., Asst. Prof., Faculty of Agriculture, Kasetsart University (50 Phaholyothin Rd., Bangkok, 10900, \\ Thailand)
}

\begin{abstract}
The objective of this study was to investigate climate based observation and satellite based indices in order to monitor agricultural drought in Thailand and to study the effect of agricultural indices on major economic crops. Standardized Precipitation Index (SPI) and remotely sensed Vegetation Condition Index (VCI) were introduced to observe drought in the central region of Thailand. Integration of SPI and VCI has demonstrated the potential of geospatial technology to analyze and identify agricultural drought areas in macro scale at near-real time. The spatial analysis of 3-month SPI distribution indicates that it was the largest area of exceptional and extremely drought in 2010. VCI time series can be used to monitor vegetation condition correlating with moisture condition and landuse type. The frequency, area extent and severity of drought assessed from SPI and VCI could be benefit for the development of mitigation strategies of drought events.
\end{abstract}

Key Words : Drought monitoring, Standardized Precipitation Index, Vegetation Condition Index

\section{INTRODUCTION}

Thailand is located in Southeast Asia and has tropical climate characterized by monsoons. There is a rainy, warm, and cloudy southwest monsoon from mid-May to September, as well as a dry, cool northeast monsoon from November to mid-March. However, drought is usually identified as principal constraint for the people during the dry season. There are 2 types of drought in Thailand. The first type is annual drought; it occurs from winter to dry season, which reduces the rainfall in upper central part of Thailand. The second one occurs in mid rainy season or late June to July. This is caused by late raining and occasionally occurs in some areas. For this reason, knowledge of the drought monitoring is an essential aspect of planning.

Earth observation data and geoinformatic systems are widely accepted tools in the establishment of integrated information. The application of Earth observation data in drought studies is now widely operative and the use of Earth observation satellite has proved to be the most cost effective means of monitoring environmental changes in terms of vegetation, rainfall and non-renewable resources ${ }^{11}$.

For drought monitoring, there are two categories of drought indices; climate based observation and satellite based observation ${ }^{2}$. However, agricultural drought monitoring needs spatially continuous data to predict it, but climate based observation provides non-continuous data from point based measurement and is usually in lacks of data in some areas. For these reasons, the alternative indices derived from satellite based will be integrated with other indices from climate based observation in order to improve drought monitoring process. 


\section{OBJECTIVE}

This study will investigate climate based observation and satellite based indices in order to monitor agricultural drought in Thailand and to study the effect of agricultural indices on major economic crops.

The study area covers 22 provinces in the Chao Phraya River basin, which is located in the central plain part of Thailand (Fig.1). The main topographic features are the lowland and some mountainous areas in the northern part.

\section{METHODOLOGY}

Severity of drought can be measured by drought indices $^{3)}$. In Thailand, varieties of drought indices are used to analyze spatial pattern of drought such as Standardized Precipitation Index $(\mathrm{SPI})^{4)}$,Perpendicular Drought Index ${ }^{5)}$ and Normalized Difference Vegetation Index (NDVI) ${ }^{6}$. For this study, SPI will be used as meteorological drought indices and so will Vegetation Condition Index or VCI be used as agricultural drought indices for potential agricultural drought monitoring. (Fig.2)

SPI is the number of standard deviations that observes cumulative precipitation deviating from the climatologically average and can be calculated for any time scale. To compute the index, a long-term time series of precipitation accumulations are used to estimate an appropriate probability of density function. The associated cumulative probability distribution is then estimated and subsequently transformed to a normal distribution. The result is the SPI, which can be interpreted as a probability using the standard normal distribution ${ }^{7)}$.

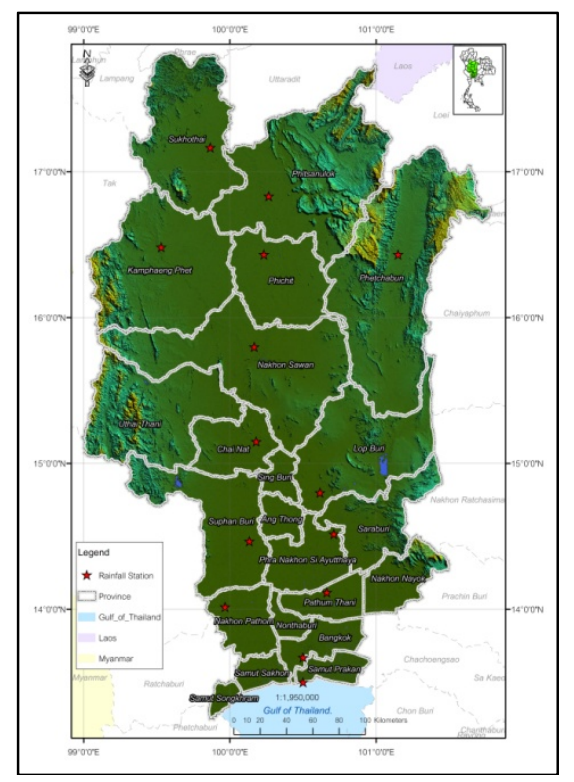

Fig.1 Study area

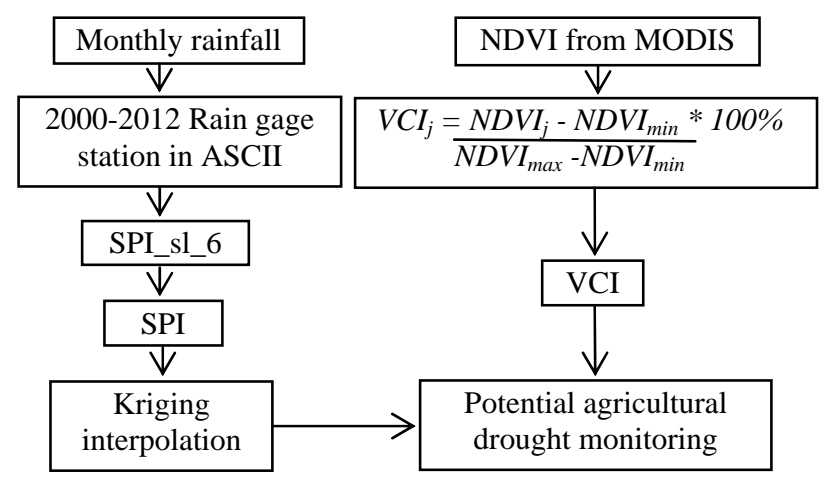

Fig.2 Methodology

Technically, the SPI is the number of standard deviations that the observed value would deviate from the long-term mean, for a normally distributed random variable. Since precipitation is not normally distributed, a transformation is first applied so that the transformed precipitation values follow a normal distribution. The Standardized Precipitation Index was designed to explicitly express the fact that it is possible to simultaneously experience wet conditions on one or more time scales, and dry conditions at other time scales, often a difficult concept to convey in simple terms to decision-makers ${ }^{8)}$.

For SPI value processing, monthly average precipitation data during January 2000 to July 2012 at 29 Thai Meteorological Department (TMD) stations are calculated by SPI_sl_6, program used to calculate Standardized Precipitation Index (SPI), provided by US. Drought Mitigation Center Input data of this program require integer data and precipitation from TMD was accurate to 0.1. Thus, the original precipitation data in unit of millimeters were converted to ten of millimeters before processing. SPI time scale intervals using in this study are 1 month, 3 month, 6 month, 9 month, and 12 month. Then, SPI values in each station are interpolated to a regular grid by the Kriging method in ArcGIS for spatial-temporal analysis and classified SPI value after U.S. Drought Monitor standard (Table 1).

To observe agricultural drought dynamically and spatially, VCI, indices derived from satellite based observations, is selected. This index was calculated from NDVI, index using to measure and monitor plant growth (vigor), vegetation cover, and biomass production from multispectral satellite data.VCI used to assess changes in the NDVI signal through time due to weather conditions, reducing the influence of 'geographic' ${ }^{\prime 9)}$ or 'ecosystem' ${ }^{10)}$ variables such as climate, soils, vegetation type and topography. 
Table 1 Drought severity classification

\begin{tabular}{|l|l|}
\hline \multicolumn{1}{|c|}{ Description } & \multicolumn{1}{c|}{ SPI value } \\
\hline No drought & -0.5 and above \\
\hline Abnormally Dry & -0.5 to -0.7 \\
\hline Moderate Drought & -0.8 to -1.2 \\
\hline Extreme Drought & -1.3 to -1.5 \\
\hline Severe Drought & -1.6 to -1.9 \\
\hline Exceptional Drought & -2.0 or less \\
\hline
\end{tabular}

Source: US. Drought Mitigation Center

It can be derived from NDVI as shown in equation (1a).

$$
V C I_{j}=\frac{N D V I_{i}-N D V I_{\min }}{N D V I_{\text {max }}-N D V I_{\text {min }}} * 100 \%
$$

Where; $\mathrm{VCI}_{\mathrm{j}}$ is the image of vegetation condition index values for date $\mathrm{j} ; \mathrm{NDVI}_{\mathrm{j}}$ is the image of NDVI values for date $\mathrm{j}$; $\mathrm{NDVI}_{\max }$ and $\mathrm{NDVI}_{\text {min }}$ are images of maximum and minimum NDVI values from all images within the data set. VCI varies from 0 to 100 ; VCI below 40 indicates stressful vegetation conditions and likely has an adverse impact from atmospheric activities, whereas VCI above 40 implies the opposite situation, not drought.

In this study, the MODIS Vegetation Index Products in 250 meters resolution at 16 days intervals since 2000 from Land Processes Distributed Active Archive Center (LP DAAC), USGS were collected to produce VCI. After calculating SPI and VCI, the measurement for drought period were regressively analyzed at varying time scale.

In order to monitor and determine the effect of drought condition, time series VCI are analyzed by changing detection between dry and wet condition in overall. Moreover, changing of VCI of selected economic crops was analyzed by overlaying land use data from Thai Agricultural Economic Office and then comparing VCI statistics in each type of crops.

\section{RESULT AND DISCUSSION}

\section{(1) SPI analysis}

SPI value from January 2000 to July 2012 from selected stations in the middle of studied area, Nakhon Sawan province, was examined using U.S. drought monitoring standard for 1-, 3-, 6-, 9-, and 12-month scales. 1 month SPI in selected station show exceptional drought in 2012 and extreme drought in 2007, 2010, and 2011, especially in dry season. (Fig.3) This 1-month time scale process is usually used to measure the short term process like that in dryland agriculture.

For 3-month SPI at the same rain gage station, it shows low SPI value or exceptional drought in 2000, 2004, 2007, 2010, and 2012 (Fig.4). The interesting point shown by Fig.4 is that exceptional drought frequency increases dramatically in this time scale.

In Fig.5 shows 6-month SPI, exceptional drought was found only in 2010 and 2012. On longer time scales, drought becomes less frequent. At the 9- and 12-month scale (Fig.6 and Fig.7), drought frequency increases but its duration decreases. It appears continuously exceptional drought in October 2004 - February 2005. The results are different by time scale because SPI calculate from cumulative rainfall value at specific time.

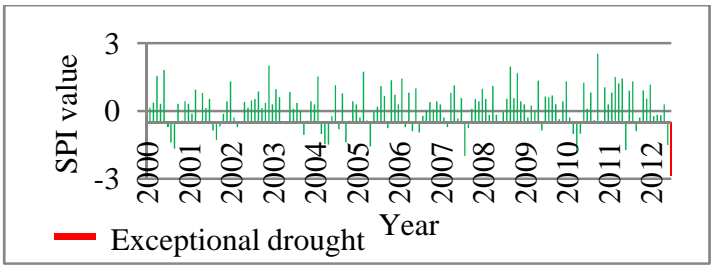

Fig.3 1-month SPI

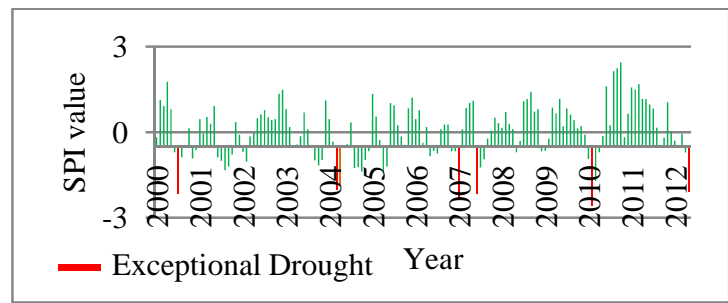

Fig.4 3-month SPI

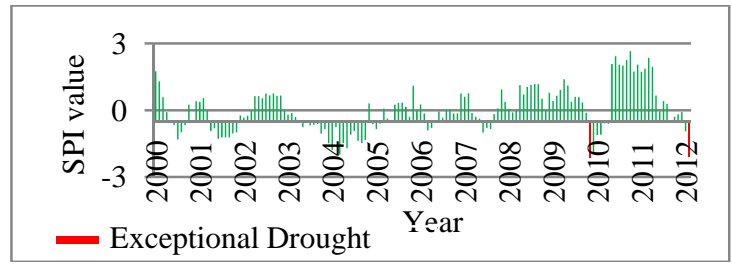

Fig.5 6-month SPI

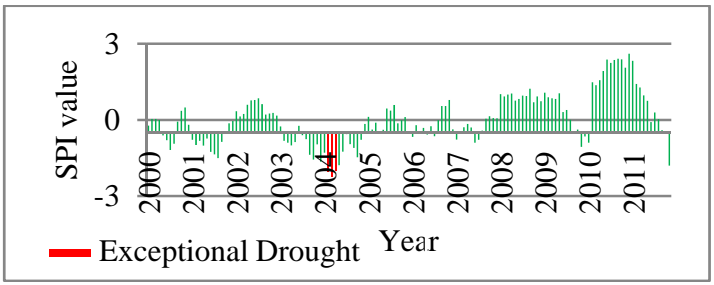

Fig.6 9-month SPI 


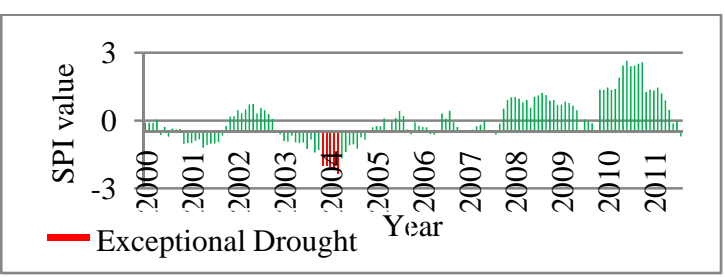

Fig.7 12-month SPI

Multi-temporal SPI analysis, 1, 3, 6, 9, and 12 months shows that extreme drought and exceptional drought appear the most frequently in SPI 3 months. It indicates that this time scale responds quickly to dry periods. However, SPI from specific location can roughly estimate the drought event.

To more precisely investigate drought, it needs to investigate in spatial-temporal aspect. SPI value in 29 stations are interpolated by Kriging method to generate spatial SPI distribution. When generating 3 -month SPI time series map during January 2000 to July 2012, it found that the strongest drought occurred in December 2004 and lower in May 2010 (shown in orange and red colors). Most of the studied area was occupied with exceptional and extreme drought (Fig.8 and Fig.9). This SPI map can locate and monitor drought better than SPI analysis from specific stations because it can obviously present distribution of drought severity with no bias and can easily applied in another drought study.

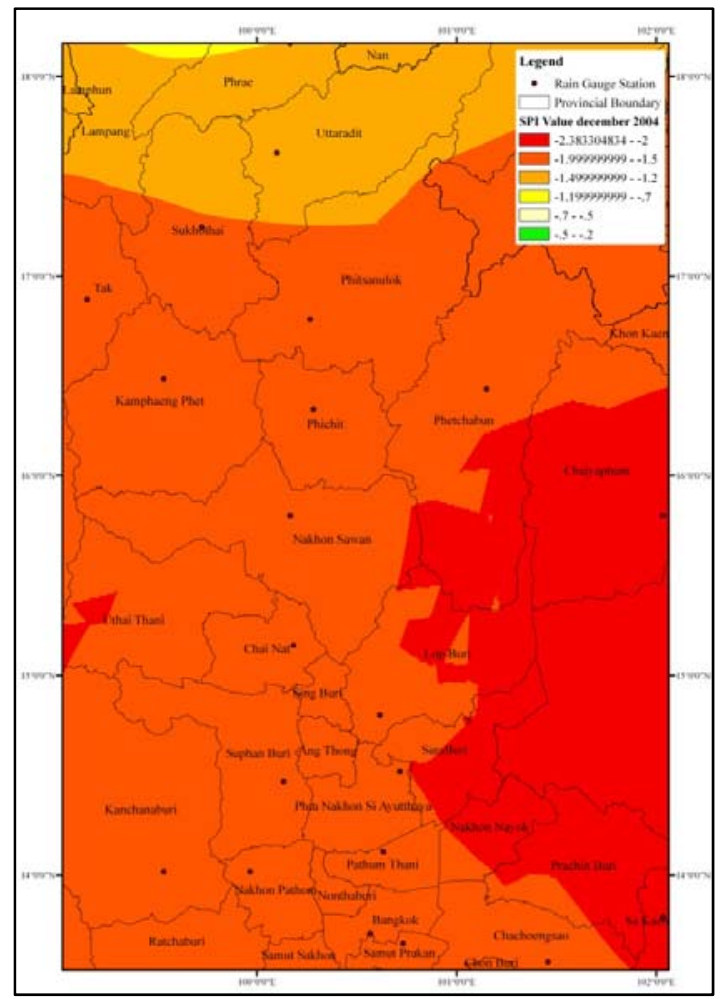

Fig.8 3-month SPI map in December 2004

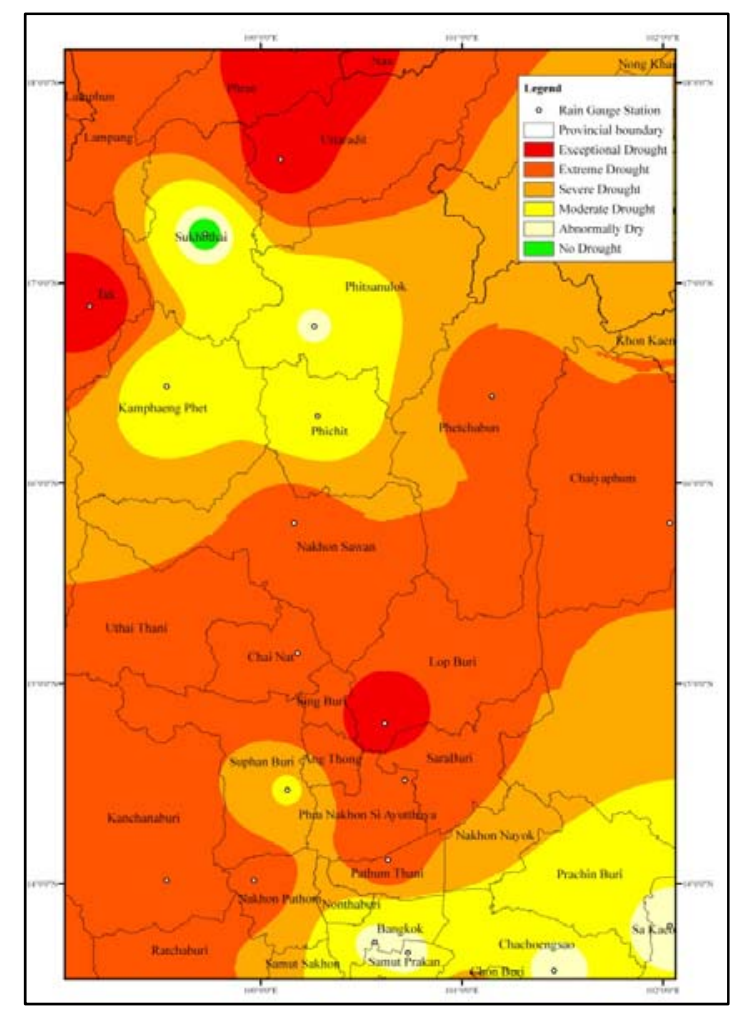

Fig.9 3-month SPI map in May 2010

\section{(2) VCI analysis}

VCI time series can be used to monitor vegetation condition. This process was analyzed by selected mean VCI value in dry season (April) and rainy season (August) during 2000 - 2012. Mean VCI value of dry and rainy season months indicates that the worst drought year was in 2010 (Fig.10). The comparison of VCI between dry and rainy season month shows less mean VCI value in dry season than rainy season every year except in 2006.

The same trend observed in the overall image was also observed for selecting land use classification to know what land use types are changing more between in dry and in wet condition. VCI in April 2010 and April 2003 are selected to overlay with land use data in GIS.

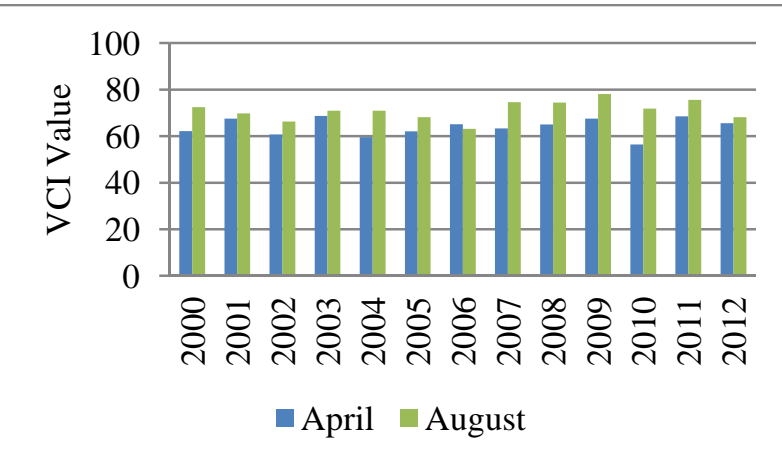

Fig.10 Mean VCI in April and May during 2000 -2012 
When comparing dry and wet condition for each land use type, it is found that cassava is changing more in mean value of VCI and the second one is corn. This may come from crop characteristics and crop calendar (Table 2). This result shows that cropland like cassava and corn was the most susceptible to drought in the term of VCI changing.

\section{(3) SPI \& VCI Correlation}

The correlation between SPI and VCI was analyzed by selecting data in dry season: March, April and May 2010, which is one of the driest of study area in 12 years and compare between SPI and VCI value in the same month. Fig.11, 12, 13 show scatter plot of VCI with 1 month SPI in the dry season. It shows that decreasing in VCI value when SPI values are reducing. The result shows a positive correlation between 1 month SPI and VCI at $\mathrm{R}^{2}=$ 0.82 in March, 0.55 and 0.65 in April and May respectively. This correlation reveals that rainfall or SPI value affects the greenness of vegetation, especially in a short time period. However, it is no relation in the longer time scale.

Table 2 Descriptive Statistic for VCI value for selected economic crops

\begin{tabular}{|l|c|c|c|}
\hline \multirow{2}{*}{$\begin{array}{c}\text { Land use } \\
\text { Types }\end{array}$} & \multicolumn{2}{|c|}{ VCI mean } & \multirow{2}{*}{$\begin{array}{c}\text { Change } \\
\text { April 2010 }\end{array}$} \\
\cline { 2 - 3 } Cassava & 46.14 & 60.17 & 23.31 \\
\hline Corn & 50.34 & 65.27 & 22.87 \\
\hline $\begin{array}{l}\text { Corn \& } \\
\text { Sugarcane }\end{array}$ & 54.74 & 66.19 & 17.29 \\
\hline Paddy field & 49.33 & 59.86 & 17.59 \\
\hline Sugarcane & 48.42 & 59.24 & 18.26 \\
\hline
\end{tabular}

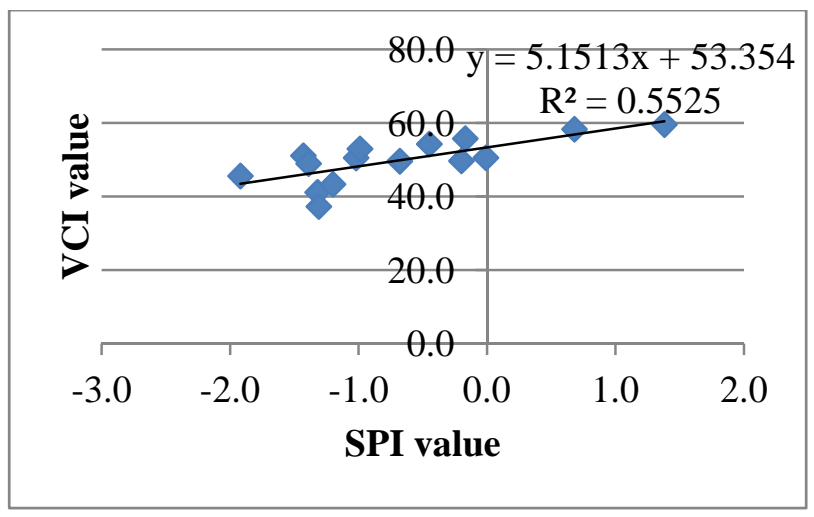

Fig.11 Correlation of VCI with 1-month SPI in March 2010

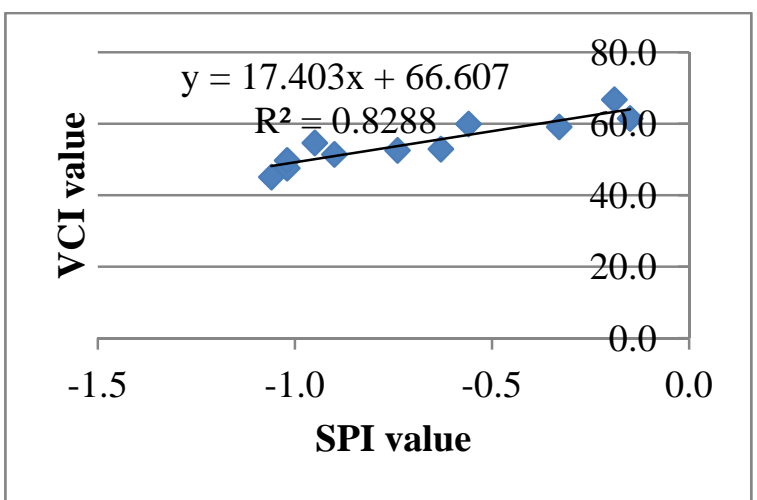

Fig.12 Correlation of VCI with 1-month SPI in April 2010

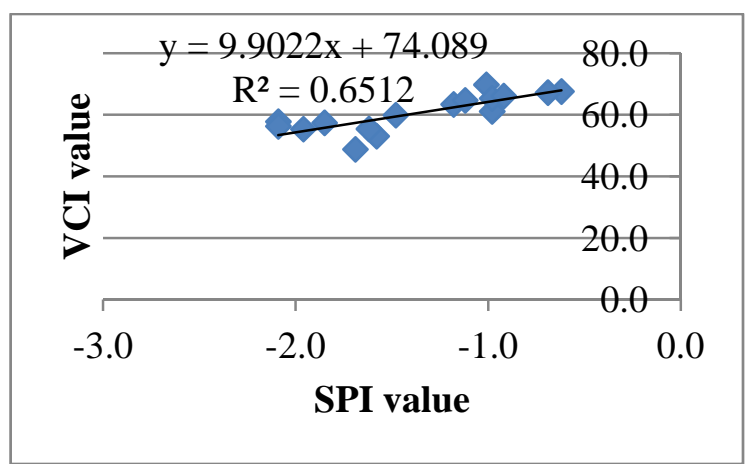

Fig.13 Correlation of VCI with 1-month SPI in May 2010

To investigate the relationship of inter-annual change, SPI and VCI value at specific rain gage station were plotted and regression was analyzed. SPI and VCI every April during 2000 - 2012 were selected to study inter-annual relationship. It found that most of them show a positive correlation but quite low correlation between SPI and VCI. However, some stations demonstrate a high correlation at $\mathrm{R}^{2}=0.8048$ and 0.628 in Phare station for correlation between 6- and 3-month SPI and VCI in April respectively (Fig.14 and Fig.15). This relationship between SPI and VCI in central region of Thailand show quite low correlation because

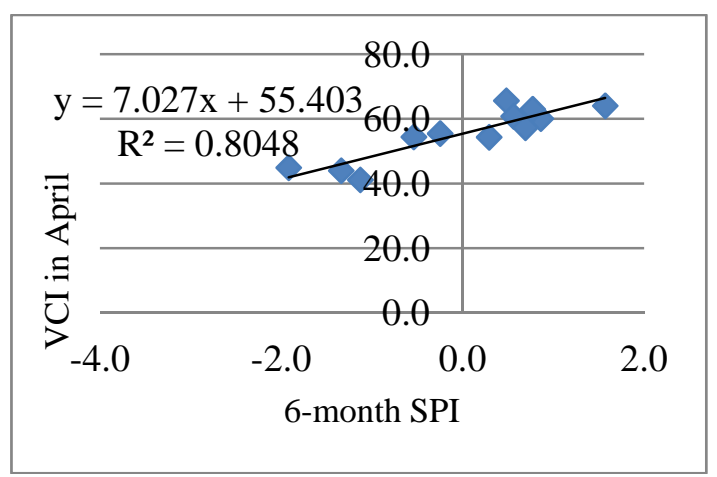

Fig.14 Correlation of VCI with 6-month SPI in April at Phrae station 


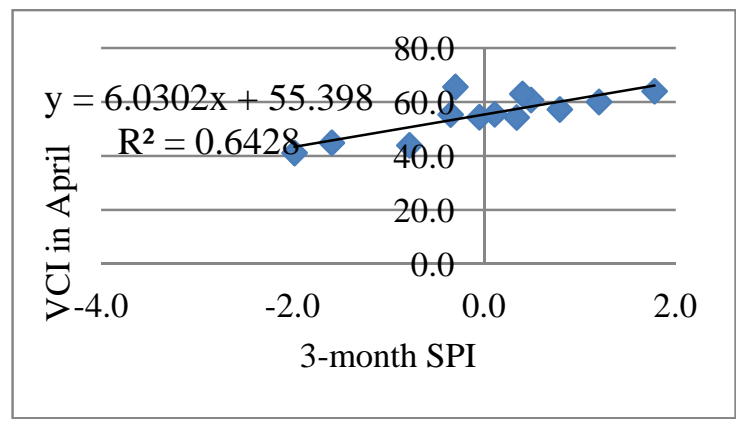

Fig.15 Correlation of VCI with 3-month SPI in April at Phrae station

there are well irrigation network in this area. The vegetation can be grown in the dry season. Whereas in the northern area, there are some stations demonstrate a high correlation because it is mountainous area and rare irrigation. Most of vegetation depends on rainfall.

\section{CONCLUSION}

Drought risk indices from integrated climate based observation and satellite based observation have demonstrated the potential of geospatial technology to analyze and identify agricultural drought areas in macro scale at near-real time, which could be an important tool to use in drought management. Overall, SPI well described the drought conditions in Thailand. The indicator established the onset, the ending, and the severity levels of exceptional drought events. Moreover, the Vegetation Condition Index from MODIS on NASA's Terra has also been shown to have a potential use in drought monitoring.

Although this study was only exploratory, the result of the drought analysis in Thailand was promising. Its potential to provide decision support information to deal with other drought indices such as in real /quasi-real time in the future was also recognized. However, before it could be used as a tool for decision makers, it would require more in-depth studies and usage of hydroinformatics. For further work, we hope to use near-real time meteorological drought index from GSMaP, so the study correlation between GSMaP and SPI must be more studied. Then, near-real time potential agricultural drought map from satellite based will be developed.
ACKNOWLEDGMENT: This work is the part of a larger study called "Integrated Hydroinformatics for Agricultural Drought Risk Assessment in the Central Region of Thailand” in the Integrated study on Hydro-Meteorological Prediction and Adaptation to Climate Change in Thailand (IMPAC-T project) that was partially supported by the Science and Technology Research Partnership for Sustainable Development, JST-JICA, Japan. The rain gauge data in the central region were made available to us by the Thai Meteorological Department.

\section{REFERENCES}

1) Suwanpraset, K. and Vathananukij, H.: Spatial Analysis and Drought Risk Determination in Thailand. J. of Res. in Eng. \& Tech., Vol.7, pp. 41-48, 2010.

2) Yagci, A. Y., Deng, M., Di L., Han, W. and Peng, C.: Vegetation Index Based Technique for Global Agricultural Drought Monitoring, 5th International Conference on Recent Advances in Space Technologies (RAST), pp. 137-141, 2011.

3) Heim, R. R.: A Review of Twentieth-Century Drought Indices Used in the United States, Bulletin of the American Meteorological Society, Vol. 83, no. 8, p. 1149, 2002.

4) Wattanakij, N., Thavorntam, W. and Mongkolsawat, C.: Analyzing Spatial Pattern of Drought in the Northeast of Thailand using Multi-Temporal Standardized Precipitation Index (SPI). Pro. ACRS 2006, Vol.1, pp. 1221-1226, 2006.

5) Prathumchai, K., Honda, K. and Nualchawee, K.: Drought Risk Evaluation using Remote Sensing and GIS: A Case Study in Lop Buri Province. Pro. ACRS 2001, Vol.1, pp. 348-353, 2001.

6) Rungsipanich, A. and Chansury, W.: Application of Perpendicular Drought Index in the Drought Assessment in Northeast Region of Thailand using MODIS Data. Pro. ACRS 2008, Vol.2, pp. 724-730, 2008.

7) McKee, T. B., Doesken, N. J. and Kleist, J.: The relationship of drought frequency and duration to time scales, Preprints, Eighth Conference on Applied Climatology, January 17-22, Anaheim, California, pp. 179-184, 1993.

8) McKee, T. B., Doesken, N. J. and Kleist, J.: Drought monitoring with multiple time scales. Ninth Conference on Applied Climatology, American Meteorological Society, Jan 15-20, 1995, Dallas TX, pp. 233-236, 1995.

9) Kogan, F. N.: Remote sensing of weather impacts on vegetation in non-homogeneous areas. Int. J. Remote Sensing, Vol.11 (8), pp. 1405-1419, 1990.

10) Kogan, F. N.: Application of vegetation index and brightness temperature for drought detection. Adv. Space Res., Vol.11, pp. 91-100, 1995. 